\title{
Mental Disorders of Bangladeshi Students During the COVID-19 Pandemic: A Systematic Review
}

\author{
Firoj al Mamun (D) ${ }^{1,2}$ \\ Ismail Hosen $\mathbb{D}^{1,2}$ \\ Jannatul Mawa Misti (D) ${ }^{1,3}$ \\ Mark Mohan Kaggwa (D) ${ }^{4}$ \\ Mohammed A Mamun (iD) ${ }^{1,2}$ \\ 'Centre for Health Innovation, \\ Networking, Training, Action and \\ Research - Bangladesh (CHINTA \\ Research Bangladesh), Savar, Dhaka, \\ 1342, Bangladesh; ${ }^{2}$ Department of Public \\ Health and Informatics, Jahangirnagar \\ University, Savar, Dhaka, 1342, \\ Bangladesh; ${ }^{3}$ Pabna Medical College, \\ Pabna, Banngladesh; ${ }^{4}$ Department of \\ Psychiatry, Faculty of Medicine, Mbarara \\ University of Science and Technology, \\ Mbarara, Uganda
}

Background: The unprecedented COVID-19 pandemic has become a global burden disrupting peoples' quality of life. Students being an important cohort of a country, their mental health during this pandemic has been recognized as a concerning issue. Therefore, the prevalence and associated risk factors of Bangladeshi students' mental health sufferings (ie, depression, anxiety, and stress) are systematically reviewed herein for the first time.

Methods: Adhering to the PRISMA guideline, a systematic search was performed from 1 to 5 April, 2021 in several databases including PubMed; and finally, a total of 7 articles were included to this review.

Results: The prevalence rates of mild to severe symptoms of depression, anxiety, and stress ranged from $46.92 \%$ to $82.4 \%, 26.6 \%$ to $96.82 \%$, and $28.5 \%$ to $70.1 \%$, respectively. The risk factors concerning mental health problems included the factors related to (i) socio-demographic (younger age, gender, lower educational grade, urban residence, family size, currently living with family/parents, and having children in the family), (ii) behavior and health (smoking status, lack of physical exercise, more internet browsing time, and dissatisfaction with sleep), (iii) COVID19 pandemic- (COVID-19 related symptoms, COVID-19 related perceptions, and fear of COVID-19 infection), (iv) miscellaneous (losing part-time teaching job, lack of study concentration, agitation, fear of getting assaulted or humiliated on the way to the hospital or home, financial problems, academic dissatisfaction, inadequate food supply, higher exposure to COVID-19 social and mass media, engaging with more recreational activities, and performing more household chores).

Conclusion: The overall assumption of mental disorders' prevalence rates can be regarded as problematic to this cohort. Thus, the authorities should consider setting up possible strategies to diminish the pandemic effect on students' mental health.

Keywords: COVID-19 and psychological impact, student mental health in Bangladesh, depression, anxiety, stress, systematic review, prevalence and risk factors, pandemic in Bangladesh

\section{Introduction}

At the end of December 2019, the COVID-19 was originated from Wuhan province, China. After a short period, it has spread out globally, turning itself to be the most challenging disaster after the World War II. ${ }^{1}$ Consequently, peoples' normal life has been reported disrupting as of its devastating effects. Therefore, on 11 March 2020, the World Health Organization declared this outbreak to be a pandemic due to its unprecedented and rampant behaviors. ${ }^{2,3}$ However, there has been 651,652 COVID-19 cases (including 9384 deaths) identified in Bangladesh, as of 7 April 2021. 
To mitigate this viral outbreak transmission in the community levels, a number of public health measures such as (i) imposing countrywide lockdown, (ii) shutting down educational institutions, (iii) isolating the infected cases, (iv) quarantining the suspected cases, (v) confining social and community movements, etc., were executed throughout the entire world. ${ }^{4-6}$ These measures are expectedly effective to suppress its transmission. For instance, $44 \%$ and $31 \%$ incident and death rates were identified for the communities with quarantine measures, whereas it was $96 \%$ and $76 \%$ for the non-quarantine communities. $^{7}$ Evidently, incident and death rates decrease after imposing these preventive measures. Although these measures have importance to suppress the outbreak, subsequent mental health impacts are not escaped, which evaluates mental health instabilities by accumulating psychological stressors like experiencing fear and panic, feeling frustrated and bored, facing a paucity of basic supplies, lacking authentic and reliable information, overwhelming with stigma, losing from jobs, and facing financial recession, etc., ${ }^{8-11}$ and these devastating issues are alleged for subsequent suicide occurrences in globally including Bangladesh. ${ }^{12-17}$ For instance, a systematic review ${ }^{18}$ reported high rates of mental health outcomes (ie, up to $50.9 \%$ anxiety, $48.3 \%$ depression, $53.8 \%$ post-traumatic stress disorder, 38\% psychological distress, and $81.9 \%$ stress were found) among the general population globally, as consistent with other literatures concerned with either multi-centered cross-sectional studies, ${ }^{19,20}$ or systematic reviews. ${ }^{6,21}$

However, on 8 March 2020, the first case of COVID-19 was confirmed in Bangladesh. ${ }^{22}$ Being a country of limited resources in the healthcare setting, the authorities imposed a countrywide lockdown to lessen its infection. ${ }^{22,23}$ During the COVID-19 pandemic, however, students' psychological health becomes a concern of interest as all the educational institutions were closed down, and their social circle, communication, and interaction processes were also changed. ${ }^{24}$ Also, online schooling, the newly introduced method of teaching can be unfavorable for a higher number of students as of difficulties related to understanding materials, technical issues, lack of interest in attending classes, limited access to online schooling materials, and so forth. ${ }^{24-26}$ Evidently, the severity of lack of willingness in online schooling led to suicide occurrences in Bangladesh. That is, an undergraduate student refused to partake online exam, that turned into conflicts within their family, as a result, the mother and son's suicide pact occurred. ${ }^{27}$ Thus, it is apparent that some of students are facing the pandemicrelated obstacles such as social and economic disruptions, uncertainty about their future careers, loneliness, fear of losing loved ones, etc. ${ }^{28,29}$

Considering the Bangladeshi students' vulnerabilities toward psychological stressors related to the current COVID-19 pandemic, several studies were conducted assessing their mental health. But, for generalization of the factors influencing mental health problems of this cohort, there is nothing but a review. To the authors' best of knowledge, no attempt to review the Bangladeshi students' mental health was made. Therefore, a systematic review was conducted herein for the first-time, considering the prevalence and risk factors of the Bangladeshi students' common mental disorders (depression, anxiety, and stress), which is anticipated to help take appropriate mental health strategies in the policy levels.

\section{Methods}

\section{Search Strategy}

For conducting a systematic review, Preferred Reporting Items for Systematic Reviews and Meta-Analyses (PRISMA) guideline ${ }^{30}$ was adhered to the present study. Thus, a systematic literature search was performed in PubMed from 1 to April 5, 2021. Within this time, additional searches were carried out on the databases such as Scopus, PsycINFO, Global Health, Web of Science, CINAHL, even Google Scholar, and ResearchGate for retrieving articles and preprints that were not indexed in PubMed. The utilizing search strategy included keywords: (depression OR anxiety OR stress OR mental health OR psychological health OR psychological impact); AND (COVID-19 OR pandemic); AND (Bangladeshi student).

\section{Study Selection Criteria}

First of all, each publication was screened based on "Titles and Abstract". Then, the full-text article was evaluated for confirming if the article to be added or not. The articles were included in this review after adhering to the inclusion criteria, including (i) being a Bangladeshi study concerned about student cohorts, (ii) being a cross-sectional study, (iii) being conducted after the pandemic initiation, (iv) utilizing established scales/tools for measurement, (v) reporting prevalence and/or risk factors of mental disorders (depression, anxiety, stress), (vi) being published in a peer-reviewed journal or preprint, and (vii) being published in the English language. 


\section{Data Eligibility}

A total of 107 articles were retrieved from several databases, whereas 103 article exists after removing the duplicate ones. Then, "Titles and Abstracts" of each articles were screened, where 92 articles were eliminated. A total of 11 full-text articles were assessed for eligibility. Finally, 7 studies were survived in the process after adhering to the inclusion criteria. Full-text articles $(n=4)$ were excluded if they were (i) review article, (ii) qualitative study (iii) mixed-method study (that is, both qualitative or quantitative) (Figure 1).

\section{Data Extraction}

In Microsoft Excel, a data extraction file was created to recruit the information from the included studies. Data were extracted utilizing the following criteria (i) first author and publication year, (ii) specific group and sample size, (iii) sampling procedure, (iv) sample characteristics, (v) assessment tool, (vi) cutoff score, (vii) prevalence rate, (viii) associated risk factors, and (ix) prevalence assessment criteria.

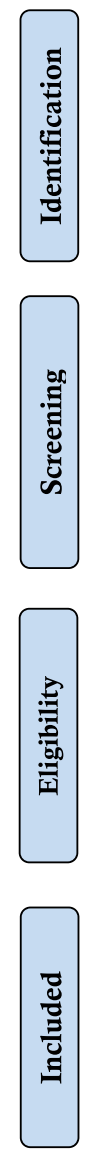

\section{Results}

\section{Description of the Included Studies}

A total of 7 cross-sectional online survey-based studies were included in this review after adhering to the inclusion criteria. ${ }^{31-37}$ All of the studies were conducted between April and May 2020. The number of participants ranged from 425 to 15,543 ; whereas only 3 studies reported participant mean age. The DASS-21 and GAD-7 were the most frequently used scale for detecting the mental disorder(s) $(n=3)$, while other scales including PHQ-9, HADS, and CESD-R-10 were also utilized. Three studies reported the prevalence rate of depression, anxiety, and stress and its associated factors while the rest of the studies reported either depression and anxiety or only anxiety (Table 1).

\section{The Prevalence Rate of Mental Disorders}

The prevalence of depression, anxiety, and stress showed fluctuation across the included studies. All but one study considered the cutoff of point for at least the presence of mild symptoms, which seems the comparison of the

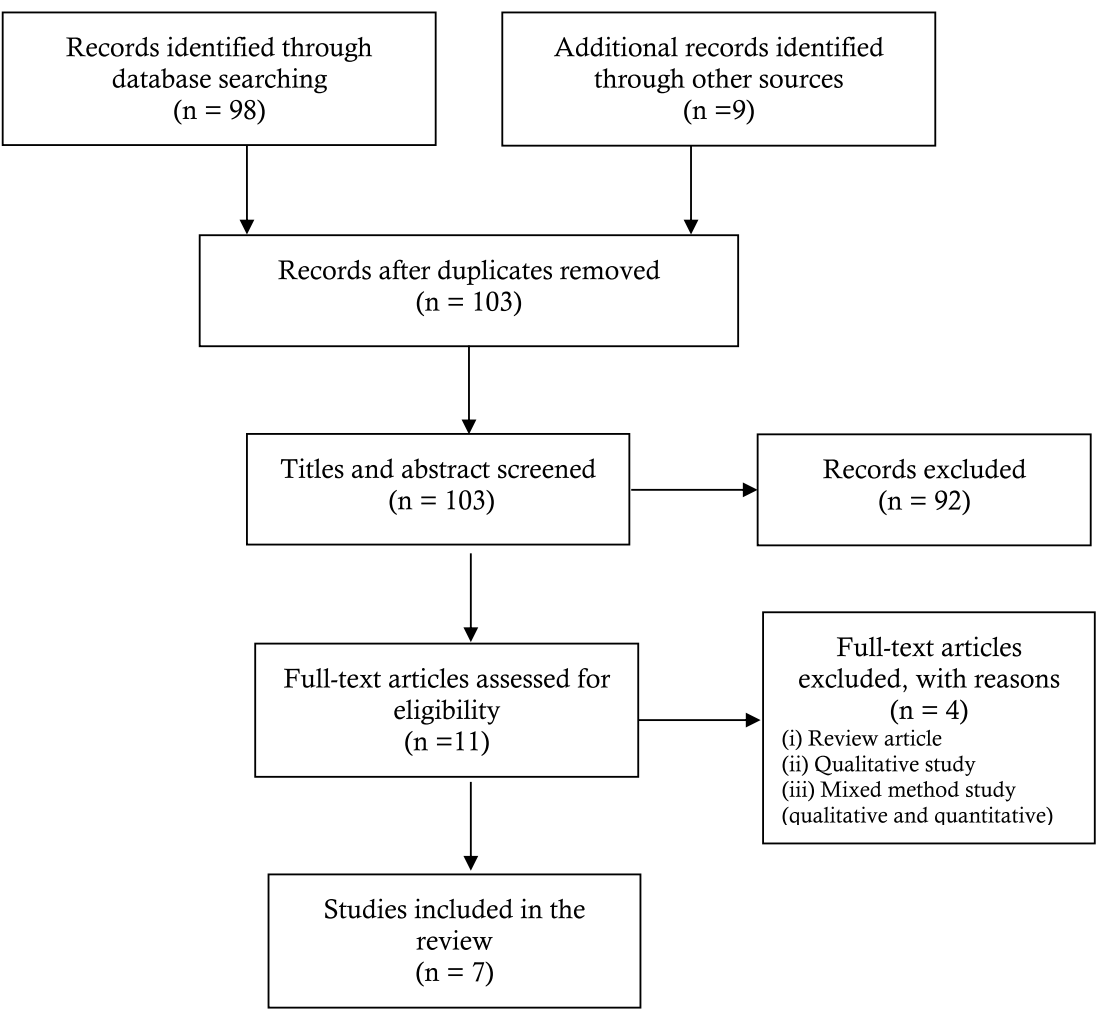

Figure I PRISMA flow-chart of the present systematic review.

Note: Adapted from Moher D, Liberati A, Tetzlaff J, Altman DG. Preferred reporting items for systematic reviews and meta-analyses: the PRISMA statement. Int J Surg. 2010;8(5):336-34I. doi:10.1016/j.ijsu.2010.02.007. ${ }^{30}$ 
Table I Characteristics of the Included Literatures to the Present Review

\begin{tabular}{|c|c|c|c|c|c|c|c|c|}
\hline $\begin{array}{l}\text { First } \\
\text { Author and } \\
\text { Publication } \\
\text { Year }\end{array}$ & $\begin{array}{l}\text { Specific } \\
\text { Group; } \\
\text { Sample } \\
\text { Size (n) }\end{array}$ & $\begin{array}{l}\text { Sampling } \\
\text { Procedure }\end{array}$ & $\begin{array}{l}\text { Sample } \\
\text { Characteristics }\end{array}$ & $\begin{array}{l}\text { Assessment } \\
\text { Tool }\end{array}$ & $\begin{array}{l}\text { Cutoff } \\
\text { Score(s) }\end{array}$ & $\begin{array}{l}\text { Prevalence } \\
\text { Rate(s) }\end{array}$ & Associated Risk Factors & $\begin{array}{l}\text { Prevalence } \\
\text { Assessment } \\
\text { Criteria }\end{array}$ \\
\hline $\begin{array}{l}\text { Sayeed et al } \\
(2020)^{31}\end{array}$ & $\begin{array}{l}\text { Students; } \\
589\end{array}$ & Snowball & NR & DASS-2I & $\begin{array}{l}A \geq 7 \\
D \geq 10 \\
S \geq 11\end{array}$ & $\begin{array}{l}\text { A: } 26.6 \% \\
\text { D: } 61.9 \% \\
\text { S: } 57.05 \%\end{array}$ & $\begin{array}{l}\text { A: Gender, age, education, family } \\
\text { income, residence, family size, negative } \\
\text { COVID-19 perceptions, and COVID- } \\
19 \text { related symptoms and social } \\
\text { stressors } \\
\text { D: Gender, age, education, family } \\
\text { income, residence, family size, under } 5 \\
\text { children in family, and negative COVID- } \\
19 \text { perceptions } \\
\text { S: Gender, age, under } 5 \text { children in } \\
\text { family, negative COVID-19 perceptions, } \\
\text { and COVID-19 related symptoms and } \\
\text { social stressors }\end{array}$ & $\begin{array}{l}\text { Mild to } \\
\text { extremely } \\
\text { severe }\end{array}$ \\
\hline $\begin{array}{l}\text { Islam et al } \\
(2020)^{36}\end{array}$ & $\begin{array}{l}\text { University } \\
\text { students; } \\
476\end{array}$ & Snowball & NR & $\begin{array}{l}\text { GAD-7 and } \\
\text { PHQ-9 }\end{array}$ & $\begin{array}{l}A \geq 5 \\
D \geq 5\end{array}$ & $\begin{array}{l}\text { A: } 81.8 \% \\
\text { D: } 82.4 \%\end{array}$ & $\begin{array}{l}\text { D and A: Private tuition during } \\
\text { COVID-19, lagging academically, living } \\
\text { with family }\end{array}$ & $\begin{array}{l}\text { Mild to } \\
\text { extremely } \\
\text { severe }\end{array}$ \\
\hline $\begin{array}{l}\text { Safa et al } \\
(2021)^{32}\end{array}$ & $\begin{array}{l}\text { Medical } \\
\text { students; } \\
425\end{array}$ & $\begin{array}{l}\text { Convenience } \\
\text { and snowball }\end{array}$ & $\begin{array}{l}\text { Age group: } 18 \text { to } \\
28 \text { years; Mean } \\
\text { age: } 22 \pm 1.81 \text { y }\end{array}$ & HADS & $\begin{array}{l}\text { Both } \\
\text { A and } \\
D>8\end{array}$ & $\begin{array}{l}\text { A: } 65.9 \% \\
\text { D: } 49.9 \%\end{array}$ & $\begin{array}{l}\text { A: Fear of getting infected, fear of } \\
\text { getting assaulted or humiliated on the } \\
\text { way to hospital or home, lack of } \\
\text { concentration on study, agitation. } \\
\text { D: Gender, fear of getting infected with } \\
\text { COVID-19, agitation. }\end{array}$ & Mild to severe \\
\hline $\begin{array}{l}\text { Khan et al } \\
(2020)^{37}\end{array}$ & $\begin{array}{l}\text { College and } \\
\text { University } \\
\text { students; } \\
505\end{array}$ & Convenience & NR & DASS-2I & NR & $\begin{array}{l}\text { A: } 33.3 \% \\
\text { D: } 46.92 \% \\
\text { S: } 28.5 \%\end{array}$ & $\begin{array}{l}\text { A: Cough, fatigue, fever, throat pain, } \\
\text { difficulty breathing, financial } \\
\text { uncertainty, fear of infection, } \\
\text { inadequate food supply, exposure to } \\
\text { COVID-19 news in social media and } \\
\text { mass media. } \\
\text { D: Fatigue, difficulty breathing, } \\
\text { Recreational activity (eg, watching TV } \\
\text { series, reading story books, online and } \\
\text { offline gaming etc.), physical exercise, } \\
\text { household chores, financial uncertainty, } \\
\text { inadequate food supply, exposure to } \\
\text { COVID-19 news in social and mass } \\
\text { media } \\
\text { S: Perceived COVID-19 symptoms (ie, } \\
\text { dry cough, fever, difficulty breathing), } \\
\text { Recreational activity (eg, watching TV } \\
\text { series, reading story books, online and } \\
\text { offline gaming etc.), financial } \\
\text { uncertainty, exposure to COVID-19 } \\
\text { news in social media and mass media }\end{array}$ & $\begin{array}{l}\text { Mild to } \\
\text { extremely } \\
\text { severe }\end{array}$ \\
\hline $\begin{array}{l}\text { Faisal et al } \\
(2021)^{33}\end{array}$ & $\begin{array}{l}\text { University } \\
\text { students; } \\
874\end{array}$ & Snowball & $\begin{array}{l}\text { Age group: } 17 \text { to } \\
38 \text { years; Mean } \\
\text { age: } 22.83 \pm 2.79 y\end{array}$ & $\begin{array}{l}\text { GAD-7 and } \\
\text { CESD-R-10 }\end{array}$ & $\begin{array}{l}A \geq 10 \\
D \geq 10\end{array}$ & $\begin{array}{l}\text { A: } 40 \% \\
\text { D: } 72 \%\end{array}$ & $\begin{array}{l}\text { A and D: Worrying about the effects of } \\
\text { COVID-19 }\end{array}$ & $\begin{array}{l}\text { A: Moderate } \\
\text { to severe } \\
\text { D: NR }\end{array}$ \\
\hline $\begin{array}{l}\text { Islam et al } \\
(2020)^{34}\end{array}$ & $\begin{array}{l}\text { University } \\
\text { students; } \\
3122\end{array}$ & Convenience & $\begin{array}{l}\text { Age group: } 18 \text { to } \\
29 \text { years; Mean } \\
\text { age: } 21.4 \pm 2 \text { y }\end{array}$ & DASS-2I & $\begin{array}{l}A \geq 8 \\
D \geq 10 \\
S \geq 15\end{array}$ & $\begin{array}{l}\text { A: } 71.5 \% \\
\text { D:76.1\% } \\
\text { S: } 70.1 \%\end{array}$ & $\begin{array}{l}\mathrm{D}, \mathrm{A} \text {, and } \mathrm{S} \text { : Gender, age, having } \geq 5 \\
\text { family members, residence, physical } \\
\text { exercise, sleep dissatisfaction, more } \\
\text { internet time, academic dissatisfaction } \\
\text { due to the COVID-19 circumstances, } \\
\text { and smoking status }\end{array}$ & $\begin{array}{l}\text { At least mild } \\
\text { symptoms }\end{array}$ \\
\hline
\end{tabular}

(Continued) 
Table I (Continued).

\begin{tabular}{|l|l|l|l|l|l|l|l|}
\hline $\begin{array}{l}\text { First } \\
\text { Author and } \\
\text { Publication } \\
\text { Year }\end{array}$ & $\begin{array}{l}\text { Specific } \\
\text { Group; } \\
\text { Sample } \\
\text { Size (n) }\end{array}$ & $\begin{array}{l}\text { Sampling } \\
\text { Procedure }\end{array}$ & $\begin{array}{l}\text { Sample } \\
\text { Characteristics }\end{array}$ & $\begin{array}{l}\text { Assessment } \\
\text { Tool }\end{array}$ & $\begin{array}{l}\text { Cutoff } \\
\text { Score(s) }\end{array}$ & $\begin{array}{l}\text { Prevalence } \\
\text { Rate(s) }\end{array}$ & $\begin{array}{l}\text { Associated Risk Factors } \\
\text { Assessment } \\
\text { Criteria }\end{array}$ \\
\hline $\begin{array}{l}\text { Dhar et al } \\
(2020){ }^{35}\end{array}$ & $\begin{array}{l}\text { University } \\
\text { students; } \\
\text { I5,543 }\end{array}$ & NR & NR & GAD-7 & NR & A: 96.82\% & $\begin{array}{l}\text { Gender, residence, living with their } \\
\text { parents, financial condition, being } \\
\text { infected with COVID-19 } \\
\text { among } \\
\text { relatives or friends }\end{array}$ \\
\hline
\end{tabular}

Abbreviations: A, anxiety; D, depression; S, stress; NR, not reported; PHQ, Patient Health Questionnaire; GAD, Generalized Anxiety Disorder; HADS, Hospital Anxiety and Depression Scale; DASS-2I, Depression, Anxiety, Stress Scale 2I; CESD-R-10, Center for Epidemiologic Studies Depression Scale Revised.

prevalence rates across the included studies to be more reliable. However, details about the prevalence rate of mental disorders are discussed below.

\section{Depression}

A total of 6 studies reported the prevalence of depression, ranging from $46.92 \%$ to $82.4 \%$ among both college and university students, ${ }^{37}$ and university students, ${ }^{36}$ respectively. However, studies considering the university students found the rate to be within $72 \%$ to $82.4 \%,{ }^{33,34,36}$ whereas $49.9 \%$ was reported for medical students. ${ }^{32}$ Also, a $61.9 \%$ prevalence rate of depression was identified in a study, although detail about the student status was not mentioned in that study. ${ }^{31}$

\section{Anxiety}

The prevalence of anxiety was determined in all of the included articles, ranging from $26.6 \%$ to $96.82 \%$. Within the university students, the anxiety rate was noted to be $40 \%$ to $96.82 \%,{ }^{33-36}$ where the lowest prevalence rate $(40 \%)$ was detected by moderate to a severe cutoff scheme, which leads to a reasonably lower anxiety rate to that rate compared to other studies'. ${ }^{33}$ However, $65.9 \%$ of medical students reported being anxious, ${ }^{32}$ whereas it was $33.3 \%$ for both college and university students. ${ }^{37}$

\section{Stress}

The prevalence of stress was reported in three studies utilizing the same instrument (that is, DASS-21), and found its range within $28.5 \%$ to $70.1 \%$. Khan et $\mathrm{al}^{37}$ reported the lowest stress prevalence rate among the college and university students, whereas university students were identified as dominantly stressed. The rest of the study within the students (no specific information regarding the student status was mentioned), found $57.05 \%$ of the participants to be suffering from stress. ${ }^{31}$

\section{Risk Factors Associated with Mental Disorders}

Risk factors of mental disorders are divided into four categories - (i) socio-demographic factors, (ii) behavior and health-related factors, and (iii) COVID-19 related factors, and (iv) other factors. However, details about the mental health risk factors are discussed below.

\section{Socio-Demographic Risk Factors \\ Age}

Two studies predicted age as a significant risk factor for psychological suffering. ${ }^{31,34}$ Sayeed et $\mathrm{al}^{31}$ found that less than or equal 22 years (vs more than 22 years) old students were at 4.49-, 4.46- and 3 times higher risk of depression, anxiety, and stress, respectively. Whereas, 18 to 24 years old students were observed to be prone to these disorders than those who had reported being aged 25 to 29 years. ${ }^{34}$

\section{Gender}

The relationship between gender and mental disorders was significant in a total of 4 studies, where all but one study found females to be at higher risk. ${ }^{31,32,34,35}$ For instance, females were at 3.44-, 3.44- and 4.54- times higher risk of depression, anxiety, and stress, respectively, ${ }^{31}$ which is similar to other studies. ${ }^{32,34}$ But, the unusual finding, that is, male students were found to be more anxious in a study compromised with a total of 15,543 university students. ${ }^{35}$

\section{Family Monthly Income}

Lower family income was significantly associated with increasing the risk of mental health disorders. ${ }^{31}$ The only study reported that students with a family income of less than or equal to 2,7000 BDT [Bangladeshi Taka (currency)] were at 2.62- and 2.56- times higher risk of 
suffering from depressive and anxiety symptoms, respectively, than more than $2,7000 \mathrm{BDT}^{31}$

\section{Education}

The levels of education were predicted as a significant risk factor for mental disorders. ${ }^{31}$ The only study depicted that students of secondary education status were at 11.03- and 11.15-fold risk of anxiety and depression, respectively, than graduate and higher ones. ${ }^{31}$

\section{Residence}

A significant mental health effect was observed by the students' place of residence. ${ }^{31,34,35}$ A study depicted that students residing in urban areas were 3.22- and 3.22- times the high risk of depression and anxiety compared to the rural areas' ones. ${ }^{31}$ Besides this, other studies reported people living in urban areas were more vulnerable to psychological problems. ${ }^{34,35}$

\section{Family Size}

The number of family members was found as a significant risk factor for mental health disorders. Sayeed et al reported that students who had a family size less than or equal to 4 were at 1.89 - and 1.91-times high risk of anxiety and depressive symptoms than family size greater than $4 .{ }^{31}$ Adversely, another study found that having more than or equal to five family members compared to less than four family members were more prone to mental disorders. $^{34}$

\section{Number of Children in the Family}

The number of children in the family was identified as a risk factor for mental health problems. ${ }^{31}$ More detailly, the study found students from these families with children under 5 years were at 2.32 times higher risk of developing depressive symptoms. ${ }^{31}$

\section{Living with Family or Parents}

Living with family or parents was also found to increase the risk of psychological suffering. ${ }^{36}$ Participants who reported currently living with their family were at 2.6and 1.8- times higher risk of depression and anxiety, respectively, ${ }^{36}$ whereas did not live with parents increased the rate of anxiety. ${ }^{35}$

\section{Behavior and Health-Related Risk Factors Smoking Status}

The habit of smoking was reported as a significant factor for evaluating mental health problems. ${ }^{34}$ Islam et $\mathrm{al}^{34}$ found that these students who were engaged in smoking were more prone to psychological sufferings compared to those who were not.

\section{Physical Exercise}

The role of physical exercise on mental health was found as a significant predictor. ${ }^{34,37}$ Based on two studies, students who reported not engaging in physical exercise were at higher risk of mental disorders. ${ }^{34,37}$

\section{Internet Use Time}

Internet browsing time was found as a predictive factor of psychological disorders in only a study. ${ }^{34}$ The study reported that students reporting internet browsing for 5 to 6 hours, and more than 6 hours compared to less than 2 hours were at increased risk of psychological problems. ${ }^{34}$

\section{Satisfaction with Sleep}

Having sleep difficulties could also influence the higher risk of mental health problems. A study claimed ${ }^{34}$ that students reporting dissatisfaction with their sleep experienced higher psychological sufferings compared to those who were satisfied.

\section{COVID-I 9 Related Risk Factors COVID-19 Related Perceptions}

The perceptions about the negative impact of the COVID19 pandemic were reported as the influential factors of psychological suffering. These perceptions included that (i) normal life disrupted by the COVID-19 pandemic, (ii) negatively affecting themselves by the COVID-19 pandemic, (iii) the country's healthcare system would be overrun and people would not be able to get proper medical care, (iv) the trajectory of COVID-19 suspicion, (v) its negative impact on education like lagging academically, ${ }^{31,36}$ (vi) worrying about the effects of COVID-19. ${ }^{33}$

\section{Fear of COVID-19 Infection}

Fear of getting infected by the COVID-19 was found as a significant predictor of depression, anxiety, and stress in a couple of studies, ${ }^{31,32,37}$ whereas relatives or friends being infected with the COVID-19 had also increased the level of anxiety. ${ }^{35}$ Safa et $\mathrm{al}^{32}$ reported that students severely tensed of being contacted with the COVID-19 infected individuals were at 3.5- and 2.75-times higher risk of being anxious and depressed, respectively, than the students who had no or minimal contract. Similarly, contact with the confirmed COVID-19 cases was reported 
to be at 4- and 3.17-times higher risk of getting stressed and anxious, respectively. ${ }^{31}$

\section{COVID-19 Related Symptoms}

Mental health sufferings were also increased when students reported experiencing the COVID-19 related symptoms. For example, Sayeed et $\mathrm{al}^{31}$ reported that experiencing one and more symptoms, and at least one symptom increased the risk of stress by 1.60 and 3.06 times; whereas it was 3.02 and 4.96 times, respectively, for anxiety. Also, another study found having the symptoms of fever, dry cough, fatigue, sore throat, difficulty breathing as the influential factors of mental disorders. ${ }^{37}$

\section{Other Risk Factors}

Some other factors also reported increasing the risk of psychological sufferings. Such as (i) losing part-time teaching job (that is, serving as a tutor) ${ }^{36}$ (ii) reporting lack of concentration on the study, ${ }^{32}$ (iii) being agitated more easily, ${ }^{32}$ (iv) fear of getting assaulted or humiliated on the way to the hospital or home, ${ }^{32}$ (v) worsening their financial condition, ${ }^{35,37}$ (vi) being dissatisfied with academic studies, ${ }^{34}$ (vi) having an inadequate food supply, ${ }^{37}$ (viii) being more exposed to the COVID-19 news in social media and mass media, ${ }^{37}$ (ix) being more active in recreational activities (ie, watching TV series, reading storybooks, online and offline gaming, etc.), (x) engaging in household chores, ${ }^{37}$ etc.

\section{Discussion}

During the pandemic, several public health measures were already implemented in Bangladesh, which is being alleged for aggravating the risk of mental instabilities. Besides this, the online learning process, the alternative way of running educational activities after the inception of the pandemic, reportedly plays a significant role in exacerbating psychological sufferings. ${ }^{24-26}$ Online schooling turns to issues related to lack of concentration on the study, agitation, dissatisfaction with academic studies, which are reported for intensifying psychological burdens. ${ }^{32,34}$ Therefore, student cohorts are allegedly at risk of mental health sufferings because of lockdown-related issues.

The present review is the first systematic approach considering students' mental health problems during the COVID-19 pandemic in Bangladesh, which is anticipated to be helpful for the mental health authorities. However, students are found at immense risk of psychological suffering, that is, the prevalence rate of depression, anxiety, and stress ranges from $46.92 \%$ to $82.4 \%, 26.6 \%$ to $96.82 \%$, and $28.5 \%$ to $70.1 \%$, respectively. These prevalence rates across studies may vary because of utilizing different tools, and cutoff scores of the same instrument. ${ }^{38}$ Besides this, pandemic-related issues such as COVID-19 infection rate of the participants' area, history of the COVID-19 infection, financial difficulties, etc., may increase the probability of higher mental health suffering. ${ }^{32,37,39-42}$ These issues are not identified across the included studies, which limits the generalizability of the findings. Despite these limitations of the included studies, the estimated prevalence rates of mental disorders are supposed to be helpful in representing the cautious situation rather than reflecting as factual findings.

Based on the present findings, mental disorders' risk factors related to basic socio-demographics included younger age, gender, lower family monthly income, lower grade education status, urban residence, family size, living with family/parents, and having children in the family. Also, behavior and health-related mental health risk factors included being smokers, lack of physical exercise, reporting more internet use time, and dissatisfaction with sleeping status. The COVID-19 pandemic related negative perceptions and social stressors, COVID-19 related symptoms, fear of COVID-19 infection, fear of getting assaulted or humiliated on the way to hospital or home acted as the triggers to escalate mental sufferings. Study found that COVID-19 patients were at higher risk of psychological suffering than psychiatric patients and healthy control individuals. ${ }^{43}$ Finally, other risk factors included losing the part-time teaching job, lacking concentration on the study, agitation, fear of getting assaulted or humiliated on the way to hospital or home, financial problems, having dissatisfaction with academic studies, having an inadequate food supply, being more exposed to COVID-19 related news, engaging with more recreational activities (ie, watching TV series, reading storybooks, online and offline gaming, etc.), performing more household chores, etc.

Being a resource limited country, Bangladesh has lack of capability to combat the current awful situation. ${ }^{22,44}$ Therefore, involving medical students in the health sector might be effective to fight against the COVID-19 pandemic in both hospital settings and community levels. ${ }^{45}$ Focus on mental wellbeing activities during the pandemic is not possibly started actioning to the country as expected. But, it has become urgent for the health authorities to initiate appropriate measures concerning the psychological sufferings of this cohort, where the present review might have some potential 
implications. First of all, based on the present findings (eg, mental health problem risk factors), special attention should be provided to the risky individuals considering their vulnerability towards serious psychological disorders. Also, the mental health or educational institutes' authorities are suggested to arrange frequent webinars on mental health wellbeing to motivate and facilitate students taking care of their mental health problems. These webinars should also be concerned with the de-stigmatization of mental health issues. Besides, the government should provide beneficial funds considering the financial conditions of the respective students' families, which might be able to reduce the student's mental sufferings if they are needy. An individual effort like avoiding smoking, taking part in regular physical exercise (at least daily 30 minutes running, cycling, gym, and so on), browsing less internet, and sleeping adequately might decrease the psychological impacts on students. In addition, the most evidence-based treatment is cognitive behavior therapy (CBT), especially internet-based CBT that can be helpful for mental health interventions during the pandemic. $^{46,47}$ Finally, the authority should command on the media/news channel not to spread misinformation, because social media exposure also triggered the mental state of the students.

\section{Conclusions}

Psychological sufferings of the Bangladeshi students during the pandemic are reported reasonably high. The present review provides an initial overview of depression, anxiety and stress prevalence rates and associated risk factors among Bangladeshi students during the COVID-19 pandemic. Thus, this systematic approach might be a strength for the policymakers of the country to take necessary steps considering the findings reported herein.

\section{Ethics Statements}

Being review on secondary data, ethical approval was not applicable for this study. Besides, there was no conflict of interest in relation to present work as informed consent was inapplicable.

\section{Acknowledgments}

The authors would like to acknowledge that their affiliation, the CHINTA Research Bangladesh, was formerly known as the Undergraduate Research Organization.

\section{Funding}

The present study did not get any financial support.

\section{Disclosure}

The authors of the paper do not have any conflict of interest. The authors involved in this research communication do not have any financial and personal relationships with other people or organizations that could inappropriately influence (bias) their work.

\section{References}

1. UNDP. COVID-19 pandemic response; 2020 . Available from: https://www.bd.undp.org/content/bangladesh/en/home/coronavirus/. Accessed May 14, 2021.

2. BBC NEWS. Coronavirus confirmed as pandemic by World Health Organization; 2020. Available from: https://www.bbc.com/news/world51839944. Accessed May 10, 2021.

3. Puspitasari IM, Yusuf L, Sinuraya RK, Abdulah R, Koyama H. Knowledge, attitude, and practice during the COVID-19 pandemic: a review. $J$ Multidiscip Healthc. 2020;13:727-733. doi:10.2147/ JMDH.S265527

4. Islam SMDU, Bodrud-Doza M, Khan RM, Haque MA, Mamun MA. Exploring COVID-19 stress and its factors in Bangladesh: a perception-based study. Heliyon. 2020;6(7):e04399. doi:10.1016/j. heliyon.2020.e04399

5. Brooks SK, Webster RK, Smith LE, et al. The psychological impact of quarantine and how to reduce it: rapid review of the evidence. Lancet. 2020;395(10227):912-920. doi:10.1016/S0140-6736(20)30460-8

6. Hossain MM, Sultana A, Purohit N. Mental health outcomes of quarantine and isolation for infection prevention: a systematic umbrella review of the global evidence. Epidemiol Health. 2020;42: e2020038. doi:10.4178/epih.e2020038

7. Nussbaumer-Streit B, Mayr V, Dobrescu AI, et al. Quarantine alone or in combination with other public health measures to control COVID-19: a rapid review. Cochrane Database Syst Rev. 2020;4 (4):CD013574. doi:10.1002/14651858.CD013574.pub2

8. Sakib N, Bhuiyan AKMI, Hossain S, et al. Psychometric validation of the Bangla Fear of COVID-19 Scale: confirmatory factor analysis and Rasch analysis. Int J Ment Health Addict. 2020. doi:10.1007/ s11469-020-00289-x

9. Sakib N, Akter T, Zohra F, Bhuiyan AKMI, Mamun MA, Griffiths MD. Fear of COVID-19 and depression: a comparative study among the general population and healthcare professionals during COVID-19 pandemic crisis in Bangladesh. Int $J$ Ment Health Addict. 2021. doi:10.1007/s11469-020-00477-9

10. Mamun MA, Sakib N, Gozal D, et al. The COVID-19 pandemic and serious psychological consequences in Bangladesh: a population-based nationwide study. $J$ Affect Disord. 2021;279:462-472. doi:10.1016/j.jad.2020.10.036

11. al Mamun F, Gozal D, Hosen I, Misti JM, Mamun MA. Predictive factors of insomnia during the COVID-19 pandemic in Bangladesh: a GIS-based nationwide distribution. Sleep Med. 2021. doi:10.1016/j. sleep.2021.04.025

12. Bhuiyan AKMI, Sakib N, Pakpour AH, Griffiths MD, Mamun MA. COVID-19-related suicides in Bangladesh due to lockdown and economic factors: case study evidence from media reports. Int J Ment Health Addict. 2020. doi:10.1007/s11469-020-00307-y

13. Dsouza DD, Quadros S, Hyderabadwala ZJ, Mamun MA. Aggregated COVID-19 suicide incidences in India: fear of COVID-19 infection is the prominent causative factor. Psychiatry Res. 2020;290:113145. doi:10.1016/j.psychres.2020.113145

14. Panigrahi M, Pattnaik JI, Padhy SK, et al. COVID-19 and suicides in India: a pilot study of reports in the media and scientific literature. Asian J Psychiatr. 2021;57:102560. doi:10.1016/j.ajp.2021.102560 
15. Jahan I, Ullah I, Griffiths MD, Mamun MA. COVID-19 suicide and its causative factors among the healthcare professionals: case study evidence from press reports. Perspect Psychiatr Care. 2021. doi:10.1111/ppc.12739

16. Mamun MA, Ullah I. COVID-19 suicides in Pakistan, dying off not COVID-19 fear but poverty?-The forthcoming economic challenges for a developing country. Brain Behav Immun. 2020;87:163-166. doi:10.1016/j.bbi.2020.05.028

17. Kahil K, Cheaito MA, El Hayek R, et al. Suicide during COVID-19 and other major international respiratory outbreaks: a systematic review. Asian J Psychiatr. 2020;56:102509. doi:10.1016/j.ajp.2020.102509

18. Xiong J, Lipsitz O, Nasri F, et al. Impact of COVID-19 pandemic on mental health in the general population: a systematic review. $J$ Affect Disord. 2020;277:55-64. doi:10.1016/j.jad.2020.08.001

19. Wang C, Chudzicka-Czupała A, Tee ML, et al. A chain mediation model on COVID-19 symptoms and mental health outcomes in Americans, Asians and Europeans. Sci Rep. 2021;11(1):6481. doi:10.1038/s41598-021-85943-7

20. Wang C, Tee M, Roy AE, et al. The impact of COVID-19 pandemic on physical and mental health of Asians: a study of seven middle-income countries in Asia. PLoS One. 2021;16(2):e0246824. doi:10.1371/journal.pone.0246824

21. Luo Y, Chua CR, Xiong Z, Ho RC, Ho CSH. A systematic review of the impact of viral respiratory epidemics on mental health: an implication on the coronavirus disease 2019 pandemic. Front Psychiatry. 2020;11:1247. doi:10.3389/fpsyt.2020.565098

22. Anwar S, Nasrullah M, Hosen MJ. COVID-19 and Bangladesh: challenges and how to address them. Front Public Health 2020;8:154. doi:10.3389/fpubh.2020.00154

23. Hosen I, Pakpour AH, Sakib N, Hussain N, al Mamun F, Mamun MA. Knowledge and preventive behaviors regarding COVID-19 in Bangladesh: a nationwide distribution. PLoS One. 2021;16(5):e0251151. doi:10.1371/journal.pone.0251151

24. Alawamleh M, Al-Twait LM, Al-Saht GR. The effect of online learning on communication between instructors and students during COVID-19 pandemic. Asian Educ Dev Stud. 2020. doi:10.1108/ AEDS-06-2020-0131

25. Kapasia N, Paul P, Roy A, et al. Impact of lockdown on learning status of undergraduate and postgraduate students during COVID-19 pandemic in West Bengal, India. Child Youth Serv Rev. 2020;116:105194. doi:10.1016/j.childyouth.2020.105194

26. Nambiar D. The impact of online learning during COVID-19: students' and teachers' perspective. Int J Indian Psychol. 2020;8 (2):783-793. doi: 10.25215/0802.094

27. Mamun MA, Chandrima RM, Griffiths MD. Mother and son suicide pact due to COVID-19-related online learning issues in Bangladesh: an unusual case report. Int J Ment Health Addict. 2020. doi:10.1007/ s11469-020-00362-5

28. Sundarasen S, Chinna K, Kamaludin K, et al. Psychological impact of Covid-19 and lockdown among university students in Malaysia: implications and policy recommendations. Int J Environ Res Public Health. 2020;17(17):6206. doi:10.3390/ijerph17176206

29. Manzar MD, Albougami A, Usman N, Mamun MA. Suicide among adolescents and youths during the COVID-19 pandemic lockdowns: a press media reports-based exploratory study. $J$ Child Adolesc Psychiatr Nurs. 2021;34(2):139-146. doi:10.1111/jcap.12313

30. Moher D, Liberati A, Tetzlaff J, Altman DG. Preferred reporting items for systematic reviews and meta-analyses: the PRISMA statement. Int J Surg. 2010;8(5):336-341. doi:10.1016/j.ijsu.2010.02.007

31. Sayeed A, Kundu S, Al Banna MH, Hasan MT, Begum MR, Khan MSI. Mental health outcomes during the COVID-19 and perceptions towards the pandemic: findings from a cross sectional study among Bangladeshi students. Child Youth Serv Rev. 2020;119:105658. doi:10.1016/j.childyouth.2020.105658
32. Safa F, Anjum A, Hossain S, et al. Immediate psychological responses during the initial period of the COVID-19 pandemic among Bangladeshi medical students. Child Youth Serv Rev. 2021;122:105912. doi:10.1016/j.childyouth.2020.105912

33. Faisal RA, Jobe MC, Ahmed O, Sharker T. Mental health status, anxiety, and depression levels of bangladeshi university students during the COVID-19 pandemic. Int J Ment Health Addict. 2021. doi:10.1007/s11469-020-00458-y

34. Islam MS, Sujan MSH, Tasnim R, Sikder MT, Potenza MN, Van Os J. Psychological responses during the COVID-19 outbreak among university students in Bangladesh. PLoS One. 2020;15(12):e0245083. doi:10.1371/journal.pone. 0245083

35. Dhar BK, Ayittey FK, Sarkar SM. Impact of COVID-19 on psychology among the university students. Glob Challenges. 2020;4 (11):2000038. doi:10.1002/gch2.202000038

36. Islam MA, Barna SD, Raihan H, Khan MNA, Hossain MT. Depression and anxiety among university students during the COVID-19 pandemic in Bangladesh: a web-based cross-sectional survey. PLoS One. 2020;15(8):e0238162. doi:10.1371/journal.pone.0238162

37. Khan AH, Sultana MS, Hossain S, Hasan MT, Ahmed HU, Sikder MT. The impact of COVID-19 pandemic on mental health $\&$ wellbeing among home-quarantined Bangladeshi students: a crosssectional pilot study. $J$ Affect Disord. 2020;277:121-128. doi:10.1016/j.jad.2020.07.135

38. Mamun MA, Griffiths MD. The assessment of internet addiction in Bangladesh: why are prevalence rates so different? Asian J Psychiatr. 2019;40:46-47. doi:10.1016/j.ajp.2019.01.017

39. Wang C, Pan R, Wan X, et al. Immediate psychological responses and associated factors during the initial stage of the 2019 coronavirus disease (COVID-19) epidemic among the general population in China. Int J Environ Res Public Health. 2020;17(5):1729. doi:10.3390/ ijerph17051729

40. Tee ML, Tee CA, Anlacan JP, et al. Psychological impact of COVID-19 pandemic in the Philippines. $J$ Affect Disord. 2020;277:379-391. doi:10.1016/j.jad.2020.08.043

41. Wang C, López-Núñez MI, Pan R, et al. The impact of 2019 coronavirus disease (COVID-19) pandemic on physical and mental health: a comparison between China and Spain. JMIR Form Res. 2021. doi: $10.2196 / 27818$

42. Lai J, Ma S, Wang Y, et al. Factors associated with mental health outcomes among health care workers exposed to coronavirus disease 2019. JAMA Netw open. 2020;3(3):e203976-e203976. doi:10.1001/ jamanetworkopen.2020.3976

43. Hao F, Tam W, Hu X, et al. A quantitative and qualitative study on the neuropsychiatric sequelae of acutely ill COVID-19 inpatients in isolation facilities. Transl Psychiatry. 2020;10(1):355. doi:10.1038/s41398-02001039-2

44. Sayeed Al-Zaman M. Healthcare crisis in Bangladesh during the COVID-19 pandemic. Am $J$ Trop Med Hyg. 2020;103 (4):1357-1359. doi:10.4269/ajtmh.20-0826

45. Tran BX, Vo LH, Phan HT, et al. Mobilizing medical students for COVID-19 responses: experience of Vietnam. J Glob Health. 2020;10(2):20319. doi:10.7189/jogh.10.020319

46. Ho CS, Chee CY, Ho RC. Mental health strategies to combat the psychological impact of COVID-19 beyond paranoia and panic. Ann Acad Med Singapore. 2020;49(3):155-160. doi:10.47102/annalsacadmedsg. 202043

47. Zhang MWB, Ho RCM. Moodle: the cost effective solution for internet cognitive behavioral therapy (I-CBT) interventions. Technol Health Care. 2017;25(1):163-165. doi:10.3233/THC-161261 


\section{Publish your work in this journal}

Psychology Research and Behavior Management is an international, peer-reviewed, open access journal focusing on the science of psychology and its application in behavior management to develop improved outcomes in the clinical, educational, sports and business arenas. Specific topics covered in the journal include: Neuroscience, memory and decision making; Behavior modification and management; Clinical applications; Business and sports performance management; Social and developmental studies; Animal studies. The manuscript management system is completely online and includes a very quick and fair peer-review system, which is all easy to use. Visit http://www. dovepress.com/testimonials.php to read real quotes from published authors. 